\title{
ASSOCIANDO O ENSINO DE LÍNGUA E ENSINO DE LITERATURA NAS AULAS DE PORTUGUÊS DO ENSINO MÉDIO
}

\author{
Rodrigo Alves dos Santos \\ Doutor em Educação pela Universidade Federal de Minas Gerais (UFMG) \\ Professor do Centro Federal de Educação Tecnológica de Minas Gerais (CEFET-MG) \\ rodrigo.alves@cefetmg.br
}

\section{RESUMO}

A dissociação entre o ensino de língua e o ensino de literatura é um dos grandes entraves do ensino médio brasileiro, no que se refere às aulas de língua portuguesa. Neste texto, essa questão é abordada com vistas a apresentar um exemplo de opção de estratégias pedagógicas que demonstram como é possível a superação dessa separação já há tempos condenada pelo discurso regulador oficial da educação brasileira. Antes de apresentar essa opção, no entanto, o texto faz, na sua segunda parte, uma síntese dos pressupostos veiculados pelo discurso oficial que deu forma à configuração hoje desejável para as aulas de língua portuguesa do ensino médio. Nesse movimento, dialoga-se com autores nacionais e estrangeiros que têm se dedicado à produção de conhecimento acerca da formação de usuários competentes da língua materna.

Palavras-chave: ensino de língua portuguesa, ensino médio, formação de professores, formação de usuários competentes da língua.

\section{ABSTRACT}

The disassociation between the teaching of a language and the teaching of literature is an important obstacle present in Portuguese classes in Brazilian High Schools. In this study, strategic options will be presented which will demonstrate the possibility of surpassing this difficulty. This condition has occurred due to the official regulatory discourse found in the Brazilian educational system. In the study's second part, there is a summary of the assumptions transmitted by the official discourse which has given form to today's configurations of the Portuguese language taught in High School. A colloquy with national and foreign authors who have dedicated themselves to the production of knowledge referent to the formation of competent readers in their native language will be presented.

Keywords: Portuguese language teaching, high school, teacher formation, competent users of language training. 


\section{Considerações iniciais}

$\mathrm{Na}$ abertura do resumo de sua tese de doutorado, Santoro (2007), mesmo não tendo como objeto central do seu estudo a língua portuguesa, sintetiza de forma pedagógica um dos principais dilemas do ensino de língua materna nas escolas de nível médio nacionais: a persistência da separação entre o ensino de língua e o de literatura. Nesse trabalho, no entanto, há muito de interlocução com inúmeros estudiosos brasileiros e estrangeiros dos campos do conhecimento que se reúnem nas Faculdades de Letras e, mais ainda, com aqueles que, estando nas Faculdades de Educação, se detêm no estudo da leitura e das práticas de leitura realizadas em contexto escolar. Ou seja, o estudo que optamos por citar, no início deste artigo, não foi o primeiro a apontar para a dissociação entre o ensino de língua e o de literatura, tampouco foi o último. Nomes reputados nos universos acadêmicos das Letras e da Educação já deram contribuições incontestes para esse debate, tanto no Brasil (Cf. GERALDI, 1997, 2003; BUZEN, MENDONÇA 2006), quanto em Portugal (Cf. DIONÍSIO E CASTRO, 2005) - já que tratamos do ensino de língua portuguesa.

Fato que precisa ser registrado também é que não é de hoje que estudiosos de um e de outro campo do conhecimento buscam encontrar as razões pelas quais essa dissociação entre ensino de língua e ensino de literatura resiste ao tempo em vários lugares do planeta, mas em particular - para o que nos interessa - no ensino médio do Brasil (MARTINS, 2006), mesmo que os documentos reguladores oficiais nacionais desse nível de ensino (BRASIL, 1999, 2002, 2006) sejam categóricos em afirmar o contrário.

Considerando esse quadro acima resumido, o presente artigo não apresentará dados de uma investigação empírica que confirme tal situação. É interesse deste texto 
contribuir para uma reflexão que leve à ruptura já cristalizada no Ensino Médio brasileiro entre o ensino de língua e da literatura, fazendo-o por meio da apresentação de uma prática pedagógica que, tomando como ponto de partida a leitura de um texto literário, inclui a abordagem da língua, a produção textual e a execução de situações que promovam os letramentos de alunos jovens frequentadores das aulas de língua materna do terceiro ano do ensino médio. Essa nossa opção se justifica pelo fato de que, ao contrário do que tem ocorrido com o ensino de língua portuguesa no nível fundamental da educação regular, poucos são os textos acadêmicos que objetivam fornecer, para professores iniciantes e experientes, exemplos de práticas pedagógicas que rompam com a separação entre aulas de língua, portuguesa, aulas de literatura e aulas de redação que impera nos anos finais da educação básica brasileira.

Assim sendo, além destas considerações iniciais, este texto apresenta, no próximo item, uma síntese dos pressupostos veiculados pelo discurso oficial que deu forma à configuração hoje desejável para as aulas de língua portuguesa do ensino médio. Apontam-se, nessa parte do texto, em linhas gerais, algumas razões que fundamentam a dissociação entre ensino de língua e ensino de literatura tão comum nas escolas de nível médio nacionais. Apresentam-se também, nessa parte, as rupturas que são esperadas do professor de português do ensino médio em exercício tendo em vista os padrões pedagógicos já em desuso. Depois disso, dedicamo-nos a expor um exemplo de prática pedagógica de ensino de língua portuguesa que busca demonstrar como executar uma aula que envolva leitura literária, abordagens gramaticais e produção textual, voltadas para a promoção dos letramentos tão defendida por estudiosos dos campos das Letras e da Educação em contexto nacional e internacional. Finalmente, depois desse exercício imaginativo, passamos a umas rápidas reflexões finais que convidam o leitor deste escrito 
a, ancorado nas reflexões apresentadas nas discussões feitas no segundo tópico deste texto, problematizar as posturas tradicionais que vêm predominado no ensino de língua materna dos anos finais da educação básica brasileira.

Nesses termos, nosso objetivo é apresentar uma possibilidade de trabalho que possa estimular o debate nos círculos e veículos de divulgação científica que tomam como tema de reflexão a formação inicial e continuada de professores de Língua Portuguesa para o exercício profissional no ensino médio brasileiro.

\section{1. $O$ discurso regulador do atual ensino médio brasileiro e o empenho pelo fim da dissociação entre ensino de língua e ensino de literatura}

À Lei de Diretrizes e Bases que vigorou no Brasil até 1996, Lei 5.692, de 11 de agosto de 1971, costuma ser atribuída, não com rara frequência, a "responsabilidade oficial" pela configuração da disciplina de Português dos anos finais da Educação Formal de maneira tripartida, isto é, subdivida em Gramática, Redação e Literatura.

No entanto, uma reflexão mais detalhada sobre a questão permite notar que essa tripartição das disciplinas escolares de língua materna, longe de ser privilégio da língua oficial do Brasil, possui justificativas diversas, algumas de origem bem remota. Exemplo desse último caso é o fato de que essa tripartição estaria mais fortemente relacionada a uma tradição originária no ensino do latim e do grego que, desde tempos muito antigos, se caracterizava pela diferenciação, já então existente, entre Gramática, Retórica e Poética.

No caso do Brasil, conforme já discutido por alguns autores (MARINHO, 2007; MARINHO apud BARRETO, 1998; SOARES, 2001), sabe-se que, mesmo com o oficial reconhecimento da disciplina escolar de Língua Portuguesa na segunda metade do século 
XIX, o latim permaneceu, por muito tempo, como a língua prestigiada nas situações de ensino proporcionadas, então, à chamada elite; enquanto o português era uma espécie de "caminho" para chegar ao idioma do Lácio.

A culpabilização da Lei 5.692, de 11 de agosto de 1971, pela tripartição da disciplina de português poderia ser questionada também pelo fato de que seriam os documentos que melhor a configurariam, como a Resolução 8/17, de 01 de dezembro de 1971, que fixariam as disciplinas do núcleo-comum para o então Segundo Grau. No entanto, mesmo nesse documento, nota-se não uma tripartição, mas uma menção direta à dicotomização entre Língua Portuguesa e Literatura, com ênfase na Literatura Brasileira.

Outro aspecto fortemente influenciador da dissociação entre o ensino de língua e o ensino de literatura, nas escolas de educação básica do Brasil, é, como já tivemos oportunidade de argumentar (SANTOS, 2003; 2009), a configuração dos cursos de formação dos professores de português. Nesse âmbito, as escolas de ensino médio recebem forte influência do modo de organização das instituições superiores de ensino, com seus blocos de disciplinas divididas em dois "compartimentos" - Linguística e Literatura - alocados nos departamentos e Faculdades de Letras; aos quais tangencia um terceiro "compartimento" - o do ensino - costumeiramente deixado a cargo dos departamentos e faculdades de Educação. Trata-se de uma tripartição que, como confirma vastamente a literatura sobre formação de professores no Brasil (DINIZPEREIRA, 2006) e no exterior (NÓVOA, 1992), resulta no modelo de graduação no qual três anos de teorias da área específica são acrescidos de um de disciplinas pedagógicas.

A crítica à forma dicotomizada de organização da disciplina de Língua Portuguesa de um lado o ensino de língua; do outro, o ensino de literatura - dos anos finais da Educação Básica e suas consequências para a configuração do ensino de língua materna 
nas escolas brasileiras da época de sua publicação constituiu o ponto de partida da argumentação instaurada nos Parâmetros Curriculares Nacionais do Ensino Médio (PCNEM) de Língua Portuguesa, publicados entre os anos de 1999 e 2000. Assim, com vistas a atingir o seu objetivo de apresentação de uma outra forma de configuração da disciplina para o que, no início do século XX, seria chamado de novo Ensino Médio, os Parâmetros assim se posicionaram:

a disciplina na LDB no 5.692/71 vinha dicotomizada em Língua e Literatura (com ênfase em literatura brasileira). A divisão repercutiu na organização curricular: a separação entre gramática, estudos literários e redação. Os livros didáticos, em geral, e mesmo os vestibulares, reproduziram o modelo de divisão. Muitas escolas mantêm professores especialistas para cada tema e há até mesmo aulas específicas como se leitura/literatura, estudos gramaticais e produção de texto não tivessem relação entre si. Presenciamos situações em que o caderno do aluno era assim dividido (BRASIL, 1999, p. 137).

Com esse trecho, conforme já defendemos oportunamente (SANTOS, 2009), deu-se início a todo um processo de desqualificação do modo como a disciplina de Língua Portuguesa se organizava nas escolas do antigo Segundo Grau, com críticas à centralidade dada à nomenclatura e às analises estruturais (no ensino da Gramática), ao artificialismo das situações de produção de textos (na Redação), e ao predomínio da periodização e da história literárias (no caso da Literatura).

Também conforme debatemos em outro momento (SANTOS, 2014), essa discussão não foi algo inaugurado pelos PCNEM de Língua Portuguesa. Isso porque ela já se inscrevia na formação discursiva da crise da educação formal (no caso, crise do ensino da Língua Portuguesa), a qual ganhou vários divulgadores no país desde meados dos anos 
1980, quando a análise das provas de candidatos a vestibular, por exemplo, evidenciou as fragilidades do ensino de língua materna oferecido aos alunos egressos do segundo grau (SOARES, 1998; GERALDI 1997, 2003).

Assim sendo, nas páginas iniciais dos PCNEM, cuja publicação está por completar duas décadas, já estavam postas todas as "falhas" da configuração do antigo Segundo Grau que, conforme o discurso ali veiculado, deveriam ser eliminadas do novo ensino médio.

O estudo gramatical aparece nos planos curriculares de Português, desde as séries iniciais, sem que os alunos, até as séries finais do Ensino Médio, dominem a nomenclatura. Estaria a falha nos alunos? Será que a gramática que se ensina faz sentido para aqueles que sabem gramática porque são falantes nativos? A confusão entre norma e gramaticalidade é o grande problema da gramática ensinada pela escola. O que deveria ser um exercício para o falar/escrever/ler melhor se transforma em uma camisa de força incompreensível. Os estudos literários seguem o mesmo caminho. A história da literatura costuma ser o foco da compreensão do texto; uma história que nem sempre corresponde ao texto que the serve de exemplo. O conceito de texto literário é discutível. Machado de Assis é literatura, Paulo Coelho não. Por quê? As explicações não fazem sentido para o aluno (BRASIL, 1999, p. 137).

À parte as muitas polêmicas, debates, dissertações e teses geradas a partir da publicação desse documento e, em muitos casos, especificamente por causa desse trecho, o fato é que, para a configuração hoje desejável para a disciplina de Língua Portuguesa do Ensino Médio, ele marca, no discurso oficial, a demanda por um deslocamento. O importante, no ensino de língua materna nas escolas brasileiras de nível médio (e nas das etapas anteriores também, como se sabe), passou a ser, a partir de então, "concentrar o ensino não nos conteúdos da tradição gramatical ou literária, e sim 
nos usos sociais da língua" (JURADO; ROJO apud BUNZEN; MENDONÇA, 2006, p. 38). Sob esse prisma, características que se tornaram traços identitários do ensino de língua materna no antigo Segundo Grau deveriam abandonadas. Isso, em termos práticos, implicava: 1) a adoção de uma nova concepção de língua - agora fundada no interacionismo sociodiscursivo de Bakhtin e de seus seguidores; 2) a aceitação de uma nova configuração da disciplina de língua portuguesa - agora não mais separando ensino de língua e ensino de literatura; 3) a compreensão de que o ensino de língua materna, no ensino médio, teria uma outra finalidade - agora visando à formação do usuário competente da língua a partir da promoção dos letramentos; 4) o entendimento de que outro sujeito aprendiz passara a frequentar os anos finais da educação básica - agora um jovem com aspirações várias, com vontade e condições de se expressar e de defender seus posicionamentos, com acesso a uma ampla gama de conhecimento disponibilizado em suportes digitais alimentados pelas tecnologias de informação e comunicação (SANTOS, 2009, 2011). Nota-se, portanto, que, ao menos no discurso regulador oficial, são claras as demandas em relação ao ensino de língua portuguesa a ser oferecido aos jovens que hoje frequentam as salas de aula do ensino médio brasileiro.

Engana-se, porém, quem julga que o discurso oficial veiculado nos PCNEM de Língua Portuguesa e nos documentos dele derivados (BRASIL, 2002, 2006) se limitava a fazer apenas proposições em relação aos modos como dever-se-ia operacionalizar o ensino de língua materna no ensino médio. Como argumentamos em estudo anterior (SANTOS, 2009), para efetivar as mudanças acima elencadas, seria necessária não só uma reengenharia na formação inicial e continuada de professores de Língua Portuguesa para atuação no ensino médio, mas também a configuração de um outro modo de existência dos indivíduos que aspirassem a ocupar a posição de professor de língua portuguesa do 
então denominado novo ensino médio. Nesses termos, o discurso veiculado, nos documentos reguladores da disciplina de língua portuguesa, publicados entre o último decênio do século XX e o primeiro deste século XXI também almejou regular os modos de ser/agir dos indivíduos aspirantes a essa condição docente, os quais deveriam

ser um sujeito docente consciente das especificidades do público jovem com o qual interagiria nas aulas, qualificado, atualizado, sujeito tecnológico, pesquisador, leitor crítico e não preconceituoso (já que compreende e respeita as leituras extraescolares dos aprendizes, bem como as opções de leitura e posicionamento destes), mediador cultural (SANTOS, 2009, p. 177).

Todo esse movimento, portanto, alicerçou a configuração hoje desejável para as aulas de língua materna dos anos finais da educação básica, que é um pressuposto, por exemplo, do Exame Nacional do Ensino Médio - o ENEM. A despeito das inúmeras - e pertinentes - críticas que podem ser feitas à prova de Linguagens, Códigos e suas Tecnologias desse exame, não se pode ignorar as baixíssimas notas que jovens brasileiros conseguem ali alcançar, depois de mais ou menos 12 anos de escolarização, seja na prova de múltipla escolha, seja na redação.

E como seria uma aula de língua portuguesa do ensino médio alinhada com as demandas veiculadas no discurso oficial a que nos referimos no tópico anterior? Que ações e que práticas ela colocaria em movimento com vistas a alcançar a finalidade agora desejada para as aulas de língua materna oferecidas aos jovens concluintes da etapa regular da educação básica e, portanto, aspirantes ao mercado trabalho e/ou à entrada no ensino superior? Objetivando apresentar repostas a essas questões, é que propomos o exercício imaginativo a seguir, no qual apresentamos a descrição de uma aula que 
buscasse atender ao que se espera do ensino de língua materna configurado conforme as demandas atuais.

\section{Um exemplo de prática pedagógica integradora nas aulas de língua portuguesa do ensino médio}

A aula seria para uma turma de terceiro ano do ensino médio.

Pensando em alinhar sua abordagem com a perspectiva propositiva da redação do ENEM, a professora selecionaria, como tema a ser discutido, A representação da cultura caipira em diversos artefatos culturais nacionais. O texto integral de leitura obrigatória a ser acionado pelo professor, durante as aulas, seria a crônica Urupês, de Monteiro Lobato, a qual compõe o volume de mesmo nome, publicado em 1918. O texto poderia ser disponibilizado em diversos formatos para os alunos: volumes do livro na biblioteca, versões em PDF disponíveis na internet enviadas por e-mail e WhatsApp, sendo permitida a leitura compartilhada por até três pessoas.

Em sala, durante as aulas de língua materna que abordassem o tema proposto, o texto seria ferramenta indispensável de se ter em mãos, já que se trata de uma obra de vocabulário difícil e com alto nível de exigência de conhecimento acumulado na formação do leitor. Tudo isso seria contado pela professora assim que ela apresentasse o tema que seria abordado no módulo em questão. Seguindo sugestão apresentada nos PCNEM e documentos deles derivados, a professora optaria por trabalhar em módulos de aulas, agrupando-as, por algumas semanas, sob um tema que pudesse permitir a integração entre o ensino de língua e o ensino de literatura.

Antes da exploração do texto de Monteiro Lobato, a professora dividiria os alunos em grupos e proporia a apresentação de um seminário com o tema da aula. Nesse dia, a 
docente aproveitaria para fazer uma exposição sobre o gênero seminário, apresentar suas características, seu modo de organização, suas exigências formais, inclusive tratando da preocupação que os expositores deveriam ter com a vestimenta, com a postura e com a linguagem, tendo em vista que "isso tudo é texto", como ela sempre afirmara.

Separados os grupos, os alunos ficariam responsáveis por pesquisar assuntos como: definições de cultura caipira, a música caipira de Pena Branca e Xavantinho, o personagem Chico Bento, a pintura Caipira Picando Fumo - de Almeida Junior, Mazzaropi e sua presença no cinema nacional, Jeca Tatu como garoto propaganda de um reputado xarope nacional... O comando dado pela docente seria: reunir o material a partir de pesquisas feitas na biblioteca, na internet, com os familiares e, a partir isso, fazer uma exposição, com suporte em slides, de cerca de dez minutos, para a turma.

Durante as exposições, a professora iria solicitando aos alunos que registrassem informações que pudessem ser úteis para uma sistematização sobre o tema abordado naquele módulo. Ali, ela exploraria conceitos como o de variação linguística em relação às falas de alguns tipos pesquisados; abordaria a questão da construção do estereótipo do homem do interior nas imagens mostradas; trataria do preconceito linguístico na composição das personagens; discutiria o modo como se construiu uma sensibilidade romântica do homem caipira nas músicas sertanejas de ontem e sua permanência nas de hoje. Tudo isso por meio de aulas dialogadas, com perguntas propositais feitas aos grupos e aos que estivessem assistindo aos seminários. Quando necessário, a professora faria apontamentos sobre os acertos e os equívocos dos alunos em relação às características específicas do gênero seminário.

Cumprida essa etapa, a professora solicitaria, finalmente, que os alunos tentassem ler a crônica de Monteiro Lobato, advertindo-os da necessidade de se ter um bom 
dicionário ou enciclopédia à mão, física ou virtual, dado o alto grau de dificuldade do texto. Ela preferiria contar aos alunos que mesmo ela, habituada à leitura de textos mais complexos, poderia precisar de certo tempo para se apropriar do texto. Suas orientações para os alunos poderiam ser: "Quando vocês travarem em alguma parte do texto, não desistam! Tentem destravar a leitura com ajuda de um adulto, dos dicionários, das enciclopédias, ou das consultas à internet! Usem os grupos de WhatsApp de vocês para se ajudarem, vão colocando lá os sinônimos que encontrarem, para ajudar os colegas".

Na aula de exploração do texto, a professora começaria sua exposição verificando o atendimento de que não havia nenhum aluno membro dos trios combinados inicialmente sem o texto ao alcance dos olhos - fosse impresso, no aparelho celular, em um computador. Precavida, a professora teria umas cópias do texto e, ainda, o projetaria no quadro por meio do projetor multimídia da escola.

Para surpreender os alunos, a exposição começaria pela projeção, leitura e análise do segundo capítulo da obra Iracema, de José de Alencar, que os discentes já conheceriam da série anterior. Ali, atendo-se à leitura dos primeiros parágrafos, a docente exploraria o uso dos adjetivos, das comparações e da cor local pelo escritor romântico, levando os alunos à reflexão sobre as escolhas linguísticas de Alencar, tendo em vista seu público e suas intenções como autor. Recorrendo ao jogo de perguntas feitas aos alunos para forçá-los a respostas orais que permitissem o trabalho da expressão oral, o professor resgataria também informações sobre O Guarani, oura obra de José de Alencar, solicitando que os alunos descrevessem o que se lembravam/conheciam sobre o protagonista do romance. Registros no quadro e pequenas sínteses entre uma questão e outra iriam consolidando o conhecimento acumulado. 
A abordagem da crônica Urupês começaria a partir do momento em que os alunos conseguissem sistematizar quem era Peri. A professora, a partir de uma brincadeira de afirmar que desistira de ler o texto lobatiano na primeira palavra (Esboroou), questionaria os alunos sobre qual a razão de o texto de Alencar, mesmo sendo mais antigo, parecer ser mais acessível/compreensível que o de Lobato. Entre várias especulações, poderia surgir, por exemplo, a possibilidade, dita por um aluno, de que talvez os textos almejassem atingir públicos diferentes, com diferentes níveis de formação/escolarização. Empolgada, a professora solicitaria à turma que aplaudisse o autor dessa fala e pediria a todos que buscassem confirmar, com trechos do texto Urupês, como ele fora feito para um perfil de leitor esclarecido, bem informado. A partir de então, a professora exploraria o vocabulário empregado por Lobato, as inúmeras referências culturais acionadas por ele no texto e, ainda, a preferência por períodos longos, compostos, com o emprego de orações intercaladas. Nessa abordagem, a professora refletiria com os alunos sobre o emprego desse tipo de construção frasal nas redações do ENEM e nas interações sociais do dia a dia.

Em um outro momento, a professora entregaria para cada grupo de alunos uma folha com o título: Perfil do Jeca Tatu, segundo o olhar de Monteiro Lobato. Explicaria que o objetivo seria que o aluno escrevesse ali características que o escritor fora atribuindo ao Jeca. Para isso, a professora leria trechos da crônica, separando por subtemas como Jeca e a política, Jeca na feira, Jeca e a religiosidade, Jeca e a medicina, Jeca e arte, Jeca e os acontecimentos históricos da época. Feitas as sistematizações e registros, os alunos concluiriam que a representação que Lobato construíra do homem do interior era bastante pejorativa, com muitas interferências da "abordagem preconceituosa" feita pelo autor. Nesse momento, a professora aproveitaria para, no livro didático, ler a biografia do 
autor, localizando-o no seu tempo e explicando como o seu posicionamento representava todo o pensamento social de então. A professora resgataria, ainda as várias representações do caipira que foram tema dos seminários, perguntando aos alunos se elas seriam tão diferentes assim do que fora representado por Monteiro Lobato no seu texto. Assim, a conclusão a que os alunos chegariam - em maior e em menor tempo seria de que, de um modo geral, as representações do homem do interior sempre tangenciavam o estereótipo, inclusive resgatando novelas de TV que, de tempos em tempos, retratam o campo como espaço do Jeca representado pelo Monteiro Lobato.

Feito todo esse movimento, a professora sistematizaria, no quadro, as conclusões a que a turma chegara sobre o tema $A$ representação da cultura caipira em diversos artefatos culturais nacionais, retomando todo o percurso feito por ela e pela turma. Nesse momento, ela apresentaria à turma um enunciado de uma produção escrita que assim se configurava:

Com base na leitura da crônica Urupês, de Monteiro Lobato, nos textos motivadores explorados nos seminários, nos registros das discussões realizadas em sala e nos conhecimentos acumulados durante sua formação, REDIJA um texto dissertativoargumentativo na norma culta padrão da língua portuguesa sobre o tema $\boldsymbol{A}$ representação da cultura caipira em diversos artefatos culturais nacionais. Selecione, organize e relacione fatos e informações em defesa do seu ponto de vista, respeitando os direitos humanos.

Após solicitar a "leitura silenciosa da proposta de redação, fazendo marcações sobre as dúvidas que surgirem sobre o enunciado", a professora esclareceria os questionamentos e daria um tempo para que os alunos conversassem em pequenos grupos sobre o que poderia ser abordado na redação. 
O passo seguinte seria a confecção do texto, realizado em uma aula de 50 minutos, por ser o tempo médio de que os alunos dispunham para fazer essa parte da prova do ENEM. As aulas de encerramento do módulo seriam dedicadas à devolução das redações corrigidas, aos comentários conforme as competências de avaliação do EXAME e às explicações que permitissem aos alunos a superação dos desvios de emprego de norma culta padrão, de estrutura do texto, de coesão e de coerência compilados pela docente à medida em que fosse corrigindo os textos. Aos alunos com mais desvios cometidos no texto, seria dada a oportunidade de refeitura da produção, contando a orientação de um colega de turma que já superara aquele tipo de dificuldade.

\section{Reflexões finais}

O perfil de docente desejado pelo discurso oficial para o ensino médio ainda não é uma figura recorrente nas aulas de Língua Portuguesa. Nesse âmbito, muitos professores sequer têm conhecimento do que deles é demandado quando da abordagem da língua portuguesa nos anos finais da educação básica. As razões para tanto são de naturezas diversas e, até certo ponto, algo bem previsível para um país de dimensões vastas, sem uma política de formação inicial e continuada de professores comprometida de fato com a escola de educação básica na qual tais docentes vão atuar.

No exercício imaginativo proposto no tópico anterior, foi apresentada uma aula que, como é possível observar, exigiria uma ruptura com concepções arcaicas de sala de aula analógica e sem conexão digital com o mundo, de aluno/a, de professor/a e até de quais são os textos "dignos" de adentrarem ao "sagrado" espaço da escola formal. Principalmente, a aula descrita exemplifica como seria uma aula de Língua Portuguesa do 
último ano do Ensino Médio que não propusesse uma ruptura entre ensino de língua e de literatura.

No que se refere à professora, é de fácil percepção que sua postura em muito se distancia daquele modelo de docente com o qual nos habituamos nas faculdades de Letras e que, por muitos anos, reproduzimos sem conflitos nas salas de aula do ensino médio. Assim, buscou-se evidenciar que, nas aulas de Língua Portuguesa em que se deseja uma abordagem da língua materna alinhada com as atuais demandas para o ensino médio, sai de cena o perfil de professor informador acerca dos textos, das obras, dos contextos de produção e das biografias dos autores e entra em cena um novo modo de existir como docente. Modo este que passa a exigir, também, outra relação professor/aluno:

Os meios de comunicação contribuíram para a recriação das relações entre educadores e alunos, pondo em crise o professor informador, para dar lugar ao educador-estimulador, ao comunicador, ao coordenador, ao facilitador da aprendizagem, deixando de ser o aluno o receptáculo passivo da informação para converter-se em agente-ator do processo de expressão e comunicação (MUÑOZ, 2008, p. 78).

$\mathrm{Na}$ aula descrita acima, um elemento que talvez possa gerar certo incômodo para alguns leitores deste texto é a inserção, pelo docente, do uso de Tecnologias de Informação e Comunicação (TIC) na promoção do processo de aprendizagem dos alunos. No entanto, é de domínio público que não há jovem presente hoje, na escola de nível médio, que desconheça por completo as ferramentas citadas na aula descrita, assim como todos sabemos o quão desgastante tem sido a tentativa de concorrer com as TIC, opondo as nossas aulas a elas. Nesses termos, é pressuposto de uma formação escolar 
alinhada com as demandas deste século XXI a incorporação, na prática docente, do entendimento de que:

as novas tecnologias criaram novas chances de reformular as relações entre alunos e professores e de rever a relação da escola com o meio social, ao diversificar os espaços de construção do conhecimento, ao revolucionar processos e metodologias de aprendizagem, permitindo à escola um novo diálogo com os indivíduos e com o mundo (MERCADO, 2002, p. 1).

Todo esse movimento no tópico anterior supõe, como se percebe, uma ruptura com a noção de aluno já cristalizada pela escola. Dessa forma, já seria algo incompreensível desconsiderar as vivências dos alunos do ensino fundamental, sob o velho argumento de que a sua condição de menores de idade os impede de pensar autonomamente (SACRISTAN, 2005), mais incompreensível ainda é ter tal atitude em relação ao aluno do Ensino Médio. Alunos estes que, tendo vivido em média quinze anos dentro e fora da escola antes de iniciarem a última etapa da Educação Básica, já acumulam um número considerável de experiências de vida, de leitura do mundo (FREIRE, 2003) que o docente deverá saber mobilizar quando da construção dos sentidos dos textos literários.

Esse reconhecimento do aluno como sujeito ativo no processo de aprendizagem, demanda, por sua vez, um ajustamento entre as posições de professor e de aluno convencionadas pela estrutura escolar, colocando ambos, nas aulas de Língua Portuguesa, quando leitores, numa situação que exige um minimizar do distanciamento tão cristalizado entre docente e discente. Isso, contudo, sem desconsiderar o franco potencial do docente para ser um leitor mais experiente e, por isso, conduzir os processos de negociação dos sentidos de um texto $(\mathrm{KOCH}, 2009$, p. 17), reconhecendo que esse 
texto tem seus direitos e impõe limites à interpretação (ECO, 2008). Note-se que, no exercício imaginativo que fizemos no tópico anterior, o professor não se furta ao papel de condutor da reflexão proposta, bem como não abandona um conteúdo formal na abordagem dos textos que ele seleciona.

\section{Referências}

BRASIL. Ministério da Educação. Secretaria de Educação Média e Tecnológica. Parâmetros Curriculares Nacionais: ensino Médio. Brasília: Ministério da Educação, 1999.

BRASIL. Ministério da Educação. Secretaria de Educação Básica. PCNEM+ Ensino Médio: Orientações Educacionais Complementares aos Parâmetros Curriculares Nacionais. Linguagens, Códigos e suas Tecnologias. Brasília: Ministério da Educação, 2002.

BRASIL. Ministério da Educação. Orientações curriculares para o ensino médio. Linguagens, códigos e suas tecnologias / Secretaria de Educação Básica. - Brasília: Ministério da Educação, Secretaria de Educação Básica, 2006.

BUZEN, Clécio; MENDONÇA, Márcia (Orgs.). Português no ensino médio e formação do professor. São Paulo: Parábola editorial, 2006. p. 83-102.

DIONÍSIO, Maria de Lourdes; CASTRO, Rui Vieira de (Orgs.). O português nas escolas. Ensaios sobre a língua e a literatura no ensino secundário. Coimbra: Almedina, 2005. DINIZ-PEREIRA, Júlio Emílio. Formação de professores: pesquisa, representações e poder. 2 ed. Belo Horizonte: Autêntica, 2006.

ECO, Umberto. Os limites da interpretação. 2 ed. Tradução de Pérola de Carvalho. São Paulo: Perspectiva, 2008.

FREIRE, Paulo. A importância do ato de ler: em três artigos que se completam. 45 ed. São Paulo: Cortez, 2003.

GERALDI, João Wanderley. Portos de passagem. 4 ed. São Paulo: Martins Fontes, 1997. 
GERALDI, João Wanderlei. (Org.). O texto na sala de aula. São Paulo: Ática, 2003.

JURADO, Shirley; ROJO, Roxane. A leitura no ensino médio: o que dizem os documentos oficiais e o que se faz?. In: BUNZEN, Clécio; MENDONÇA, Márcia (Orgs.). Português no ensino médio e formação do professor. São Paulo: Parábola Editorial, 2006. p. 36-55.

KOCH, Ingedore G. V. Desvendando os segredos do texto. 6 ed. São Paulo: Cortez, 2009. MARINHO, Marildes. A língua portuguesa nos currículos de final de século. In: BARRETO, Elba Siqueira de Sá (Org.). Os currículos do ensino fundamental para as escolas brasileiras. Campinas/SP: Autores Associados; São Paulo: Fundação Carlos Chagas, 1998.

MARINHO, Marildes. Currículos da escola brasileira: elementos para uma análise discursiva. Revista Portuguesa de Educação, Braga/Portugal, v. 20(1), p. 163-189, jan. 2007.

MARTINS, Ivanda. A literatura no ensino médio: quais os desafios do professor?. In: BUZEN, Clécio; MENDONÇA, Márcia (Orgs.). Português no ensino médio e formação do professor. São Paulo: Parábola Editorial, 2006. p. 83-102.

MERCADO, L. P. L. A internet como ambiente auxiliar do professor no processo ensinoaprendizagem. In: Conferencia Internacional sobre Educatión, Formación y Nuevas Tecnologías y e-Learning, 2002. Sevilla, Espanha.Actas de Virtual Educa 2002. Sevilla, Espanha: Virtual Educa, 2002, v. 1. p.1-12.

MUÑOZ, R. F. Las nuevas tecnologías aplicadas a la educatión en la formación inicial del profesorado: a modo de justificatión. Docencia e Investigatión. Revista de la Escuela Universitaria de Magisterio de Toledo. Ano XXI, jan-dez, 2008. p. 77-100.

NÓVOA, António et. al. Os professores e sua formação. Tradução de Graça Cunha, Cândida Hespanha, Conceição Afonso e José António de Sousa Tavares. Lisboa: Dom Quixote, 1992.

SACRISTÁN, José Gimeno. O aluno como invenção. Porto Alegre: Artmed, 2005. SANTORO, Elisabetta. Da indissociabilidade entre ensino de língua e de literatura: uma proposta para o ensino de italiano como língua estrangeira nos cursos de Letras. 2007, 355 f. Tese (Doutorado em Letras) - Universidade de São Paulo, São Paulo, 2007. 
SANTOS, Rodrigo Alves dos. Conhecendo o perfil do jovem demandado pelo discurso oficial sobre o "novo" Ensino Médio. In: CARVALHO, Carlos Frederico Vaz de; FRAGA, Fernando Caramuru Bastos; ROSA, José Henrique Alves; ARÃO, Lilian Aparecida (Coord.). Dez olhares sobre juventude e cultura. Belo Horizonte: Fundação Guimarães Rosa, 2011. p. $75-85$.

SANTOS, Rodrigo Alves dos. Do rumor ao valor: reflexos e reflexões sobre a aula de literatura. 2003. 141f. Dissertação (Mestrado em Ciências e Práticas Educativas) Universidade de Franca, Franca, SP, 2003.

SANTOS, Rodrigo Alves dos. Do professor de literatura ao formador de leitores críticos de textos literários: um estudo sobre a (re)invenção do professor de língua portuguesa para o trabalho com a leitura literária no Ensino Médio. 199f. Tese de doutorado (Doutorado em Educação) - Faculdade de Educação - Universidade Federal de Minas Gerais, Belo Horizonte, 2009.

SANTOS, Rodrigo Alves dos. O caráter continuísta do discurso oficial sobre configuração de um sujeito docente para o trabalho com a leitura literária no Ensino Médio do século XXI. Revista Remate de Males, Campinas, SP, v. 34, n. 2, jul./dez., p. 421-441, 2014.

SOARES, Magda. Concepções de linguagem e o ensino de Língua Portuguesa. In: BASTOS, Neusa B. (Org.). Língua Portuguesa: história, perspectivas, ensino. São Paulo: EDUC, 1998. SOARES, Magda. Português na escola: história de uma disciplina curricular. In: ROSING; BECKER (Org.). Ensaios. Passo Fundo, RS: UFP, Edelbra, 2001. p. 201- 222.

Recebido em 15 de março de 2018. Aceito em 5 de maio de 2018. 